\title{
A cost analysis on the pattern of asthma prescribing in the UK
}

\author{
R.G. Neville*, M.G. Pearson**, N. Richards***, J. Patience ${ }^{+}$, S. Sondhi' ${ }^{+}$, B. Wagstaff ${ }^{+}$, N. Wells ${ }^{+}$
}

A cost analysis on the pattern of asthma prescribing in the UK. R.G. Neville, M.G. Pearson, N. Richards, J. Patience, S. Sondhi, B. Wagstaff, N. Wells. CERS Journals Ltd 1999.

ABSTRACT: There is a need to establish the proportion of adult asthmatics at each step of the recommended asthma management guidelines, the cost of their prescribed treatment, and a revised cost of treatment assuming patients who were suboptimally controlled were moved up a step.

Actual prescription and cost figures and a theoretical projection of an ideal scenario was calculated from a sample of general practices in Great Britain from the Doctors Independent Network. They comprised 102 nationally distributed practices and 17,206 adult patients with a diagnosis of, and prescription related to, asthma recorded between October 1993 and March 1994.

Ninety-one per cent of patients received treatment within a recognized step of the guidelines. Of these, $80 \%$ were at steps 1 and 2 . Employing excess inhaled beta-agonist use as a proxy for control of asthma, between $55 \%$ and $69 \%$ of patients at Steps 1-3 should receive treatment at a higher step. This could lead to an increased expenditure of up to $£ 4.66$ per adult patient per month. This would imply a rise in the annual UK cost of antiasthma prescriptions for adults from $£ 388 \mathrm{~m}$ to a possible $£ 533 \mathrm{~m}$.

The United Kingdom Government audit commission has suggested that current expenditure on asthma treatment appears to be insufficient. Using an entirely different approach this study has confirmed that a significant increase in asthma prescribing costs is likely to be needed if optimal control of asthma is to be achieved. Eur Respir J 1999; 14: 605-6l09.
*University of Dundee, **Fazakerly Hospital, Liverpool, ${ }^{* * *}$ Compufile Ltd ${ }^{+}$GlaxoWellcome UK Ltd.

Correspondence: R.G. Neville, University of Dundee, Tayside Centre for General Practice, Kirsty Semple Way, Dundee DD2 4AD, UK. Fax: 4401382633839

\section{Keywords: Asthma \\ costs \\ guidelines \\ prescribing}

\section{Received: December 101997}

Accepted after revision June 151998

R.G. Neville and M.G. Pearson received reimbursement of expenses from GlaxoWellcome UK Ltd. for work on this project.
Asthma is a major health problem and there is evidence to suggest that the disease is increasing in both prevalence and severity [1-4]. Mortality rates over the past decade have been slow to improve: in the UK 1,500 people die from asthma each year [5, 6]. Many patients suffer from symptoms both during the day and at night which impairs their quality of life [7-9].

Structured management within primary care may lead to improved symptom control and patient well being [10-13]. It is now widely accepted in clinical practice that the optimal way to manage asthma is to attempt to prevent the development of symptoms which involves patient education about the disease, regular monitoring, more effective use of medication and the appropriate choice of medication. This approach underpinned the 1993 British Thoracic Society's (BTS) guidelines [14] on the management of asthma, which imply an increasing use of prophylactic agents, essentially inhaled corticosteroid preparations.

Treatment of asthma using more prophylactic drugs, will inevitably lead to a rise in spending on antiasthma medication at a time when the UK National Health Service is seeking ways to contain expenditure growth. The UK Audit Commission suggested that therapeutic expenditure on asthma management might "legitimately" increase by $£ 75$ million per annum [15], if all general practitioners were to prescribe half as many inhaled steroids as short acting beta-agonists, a ratio currently achieved by only $10 \%$ of practices.

The objective of this study is to derive a more comprehensive and accurate figure for the additional cost that might result from the appropriate adoption of the BTS guidelines.
This study aims, 1) to estimate the proportion of adult asthmatics at each step of BTS guidelines, 2) to calculate the actual cost of their prescribed treatment, and 3) to project a revised cost assuming patients with suboptimal control were moved up one step.

\section{Method}

\section{Treatment steps and actual costs}

The Doctors' Independent Network (DIN) Torex Database comprises data from 102 practices which use Meditel (Orchard House, Bromsgrove, Worcestershire, B60 3EA) practice software. Practices are distributed throughout Great Britain and supply anonymous data which is encrypted on site and downloaded nightly to the DIN office where it is aggregated and processed in accordance with the terms of the Data Protection Act. Practices only became eligible for the study when all available historical data had been extracted from their practice system and when they were transmitting prescribing data on a daily basis. The doctors participating in the study were not aware that their asthma prescribing was the subject of study.

The demographics of the 388 general practitioners (GPs) are shown in table 1 . There was an over-representation of larger practices and an under-representation of Scottish practices. The computer records of 17,206 patients aged 18 and above from these practices with a recorded Read Code diagnosis of asthma [10] and who received a prescription for asthma therapy between October 1993 and March 1994 were analysed. Patients were assigned to steps within the BTS guidelines according to the various 
Table 1. - Distribution of practitioners by region and number of partners in study sample and nationality

\begin{tabular}{lrr}
\hline & $\begin{array}{c}\text { Study sample* } \\
(\mathrm{n}=388) \\
\mathrm{n}(\%)\end{array}$ & $\begin{array}{c}\text { Great Britain } \\
(\mathrm{n}=31,467) \\
\mathrm{n}(\%)\end{array}$ \\
\hline Region & & \\
Northern & $10(3)$ & $1671(5)$ \\
Yorkshire & $22(6)$ & $2023(6)$ \\
Trent & $36(9)$ & $2516(8)$ \\
East Anglian & $28(7)$ & $1162(4)$ \\
North-West Thames & $25(6)$ & $1982(6)$ \\
North-East Thames & $7(2)$ & $2057(7)$ \\
South-East Thames & $6(2)$ & $2013(6)$ \\
South-West Thames & $55(14)$ & $1598(5)$ \\
Wessex & $30(8)$ & $1669(5)$ \\
Oxford & $33(9)$ & $1409(4)$ \\
South-Western & $54(14)$ & $2067(7)$ \\
West Midlands & $26(7)$ & $2755(9)$ \\
Mersey & $13(3)$ & $1274(4)$ \\
North-Western & $23(6)$ & $2093(7)$ \\
Wales & $9(2)$ & $1702(5)$ \\
Scotland & $11(3)$ & $3476(11)$ \\
Number of partners & & \\
1 & $17(4)$ & $3239(10)$ \\
2 & $26(7)$ & $4286(14)$ \\
3 & $51(13)$ & $5304(17)$ \\
4 & $56(14)$ & $5732(18)$ \\
$5+$ & $238(61)$ & $12906(41)$ \\
\hline
\end{tabular}

*: "Study sample" is the number of General Practitioners from each region who supplied data; ${ }^{+}$: "Great Britain" refers to the total number of General Practitioners in each region.

therapy combinations that they received. In order to do this a number of assumptions were made which are listed as $1-6$ in the appendix.

For each BTS step, an average monthly cost of treatment per patient was calculated which reflected the number of patients in that step, and the products and dosages that they were prescribed. Appendix, 7-8.

\section{Projected costs}

The extent to which patients were well controlled was estimated using frequency of use of short-acting inhaled beta-agonists. The BTS guidelines indicate that patients should move up one step if they require an inhaled bronchodilator more than once daily. This enabled figures for the proportion of patients at each step who appeared to be receiving insufficient therapy to be derived. No patients were moved more than one step since there was no basis for doing this in the BTS guidelines. Appendix, 9-11.

A revised cost of asthma therapy was calculated by multiplying the original treatment costs for all treatment types except short acting beta-agonists by the revised patient numbers at each BTS step. See Appendix, 12, 13. Actual and projected costs were then compared to determine how much additional spending might be required by the pursuit of "ideal" asthma treatment.

This study does not attempt to consider whether adherence to the guidelines actually results in improved morbidity and mortality. Consideration of treatment costs in the wider context of total asthma management was also outside the scope of this paper, since the database used was focused only on prescribing.

\section{Results}

There were 17,206 adults who received asthma treatment linked to a Read Code diagnosis of asthma [10] between October 1993 and March 1994. 15,649 (91\%) patients were receiving treatment which could be classified according to BTS guidelines. Almost half, 8,106 $(47.1 \%)$ were at step 2 and only $2,810(16.3 \%)$ of patients were at step 3 or above. 4,733 (27.5\%) patients received no preventative therapy (see table 2 ). The remaining $1,557(9 \%)$ asthmatics were difficult to classify as they were prescribed combinations of therapies outside of those recommended by the BTS guidelines, for example: a short-acting inhaled beta-agonist and a theophylline 233 $(1.4 \%)$ asthmatics, oral steroids only $235(1.4 \%)$ and theophylline only $95(0.6 \%)$.

The distribution of patients across the guideline steps was not influenced by either the size of the practice or fundholding status.

Table 2 shows the numbers of asthmatics at each step of the BTS guidelines and the number who were poorly controlled, based upon using more than two puffs of shortacting inhaled beta-agonists each day, and should ideally be considered for an increase in prophylactic treatment.

Table 2. - Number of Asthmatics at each British Thoracic Society Guidelines Step ${ }^{\#}$

\begin{tabular}{|c|c|c|}
\hline & \multicolumn{2}{|c|}{ Asthmatics patients $^{+} \mathrm{n}(\%)$} \\
\hline & $\begin{array}{l}\text { Original } \\
\text { allocation }\end{array}$ & Reallocation \\
\hline $\begin{array}{l}\text { Step } 1 \\
\text { (short acting beta-agonists) }\end{array}$ & $4733(27.5)$ & $2110(12.3)$ \\
\hline Remain at step 1 & $2110(44.6)$ & \\
\hline Move to step 2 & $2623(55.4)$ & \\
\hline $\begin{array}{l}\text { Step } 2 \\
\text { (low-dose inhaled steroids) }\end{array}$ & $8106(47.1)$ & $6301(36.6)$ \\
\hline Remain at step 2 & $3678(45.4)$ & \\
\hline Move to step $3 \mathrm{a}$ & $2573(31.7)$ & \\
\hline Move to step 3b & $1855(22.9)$ & \\
\hline $\begin{array}{l}\text { Step 3a } \\
\text { (high-dose inhaled steroids) }\end{array}$ & $1078(6.3)$ & $2931(17.0)$ \\
\hline Remain at step $3 \mathrm{a}$ & $358(33.2)$ & \\
\hline Move to step 4 & $720(66.8)$ & \\
\hline $\begin{array}{l}\text { Step 3b } \\
\text { (extra therapy added to low } \\
\text { dose inhaled steroids*) }\end{array}$ & $778(4.5)$ & $2098(12.2)$ \\
\hline Remain at step $3 b$ & $243(31.2)$ & \\
\hline Move to step 4 & $535(68.8)$ & \\
\hline $\begin{array}{l}\text { Step } 4 \\
\text { (additional therapy) }\end{array}$ & $823(4.8)$ & $2078(12.1)$ \\
\hline Remain at step 4 & $823(100)$ & \\
\hline $\begin{array}{l}\text { Step } \mathbf{5} \\
\text { (maintenance oral steroids) } \\
\text { Remain at step } 1 \\
\text { Move to step } 2\end{array}$ & $131(0.8)$ & $131(0.8)$ \\
\hline Outside of guidelines & $1557(9.0)$ & $1557(9.0)$ \\
\hline Total & $17206(100)$ & $17206(100)$ \\
\hline $\begin{array}{l}{ }^{+}: \text {Numbers (percentages) of } \\
\text { step or moving to another ar } \\
\text { total number (per cent) of pati } \\
\text { tion and reallocation based or } \\
\text { ing beta-agonist; } * \text { : extra the } \\
\text { theophylline, cromoglycate, } \\
\text { beta-agonist. }\end{array}$ & $\begin{array}{l}\text { tients remainin } \\
\text { resented as a p } \\
\text { ts at that step; } \\
\text { requency of us } \\
\text { py comprised s } \\
\text { locromil or lon }\end{array}$ & $\begin{array}{l}\text { at the current } \\
\text { oportion of the } \\
\text { original alloca- } \\
\text { ge of short-act- } \\
\text { stained release } \\
\text {-acting inhaled }\end{array}$ \\
\hline
\end{tabular}


$55.4 \%$ of patients at Step 1 should ideally move up one step. The corresponding figures for Step 2 are $54.6 \%$, Step 3a $66.8 \%$ and Step 3 b $68.8 \%$.

Some doctors still prescribe bronchodilator inhalers to be taken regularly, therefore two subgroups were also examined: 6,386 who had always been given inhalers with the instruction to regularly take them three or four times daily and 2,726 who had consistently been told to take their inhalers only 'as required'. More of the former could be justified in a step up than the latter $(67.5 \%$ versus $59.9 \%, \mathrm{p}<0.01)$ but the large majority of high usage is not explained by the prescribing instructions.

Table 3 shows the average monthly costs per head, by therapeutic category, for each of the BTS steps in the initial analysis. Costs rose from $£ 1.84$ per month in step 1 (inhaled beta-agonists only), to $£ 45.33$ in step 5 where medicines from all of the broad therapeutic categories were used to manage asthma. When the figures were corrected for the number of patients at each step, betaagonists represent $15 \%$, low-dose inhaled steroids $51 \%$, high dose inhaled steroids $18 \%$, oral steroids $0.001 \%$ and other drugs $16 \%$ of the total asthma drug budget.

The original distribution of the 15,649 patients across the BTS steps gave rise to a total expenditure per month of nearly $£ 195,000$. Redistribution of the sample increased this cost to $£ 267,760$. The calculations suggest that the pursuit of "ideal" asthma treatment might be expected to increase total monthly prescribing costs for this sample of patients by up to $£ 72,900$ (37\%), equivalent to an additional expenditure of $£ 4.66$ per head per month. The number of patients located in the less expensive treatment steps fell with a corresponding increase at the more costly end of the treatment spectrum (table 4).

\section{Discussion}

This study shows that the "ideal" cost of antiasthma prescribing according to recommended guidelines is likely to be much greater than the current cost. If one extrapolates the figures to a "typical" general practitioner with a patient list of 2,000 and a 5.8\% adult diagnosis rate of asthma (see Appendix, 14) then the current asthma prescription cost of $£ 13,297$ annually for adults would rise by $37 \%$ to $£ 18,273$. On a national scale the cost of antiasthma prescriptions in the UK could rise from $£ 388 \mathrm{~m}$ to $£ 533 \mathrm{~m}$, an increase of $£ 145 \mathrm{~m}$ - almost twice the Audit Commission's estimate.

Table 3. - Per capita monthly treatment costs of each British Thoracic Society step by type of medication

\begin{tabular}{|c|c|c|c|c|c|c|}
\hline & \multicolumn{6}{|c|}{ Cost of step $£$ sterling } \\
\hline & 1 & 2 & $3 a$ & $3 b$ & 4 & 5 \\
\hline $\begin{array}{l}\text { Short acting beta- } \\
\text { agonist }\end{array}$ & 1.84 & 1.52 & 2.17 & 2.40 & 3.06 & 6.63 \\
\hline $\begin{array}{l}\text { Standard-dose } \\
\text { inhaled } \\
\text { corticosteroids }\end{array}$ & & 11.06 & & 11.51 & & \\
\hline $\begin{array}{l}\text { High-dose inhaled } \\
\text { corticosteroids }\end{array}$ & & & 18.26 & & 14.88 & 19.86 \\
\hline Mixed group & & 0.15 & & 17.84 & 18.88 & 18.04 \\
\hline Oral steroids & & & & & & 0.80 \\
\hline Total & 1.84 & 12.73 & 20.43 & 31.75 & 36.82 & 45.33 \\
\hline
\end{tabular}

Table 4. - Monthly costs of antiasthma medications of original allocation (stage 1) and reallocation for "good asthma management" (stage 2)

\begin{tabular}{|c|c|c|c|c|c|}
\hline \multirow[b]{2}{*}{ Step } & \multicolumn{2}{|c|}{ Stage 1} & \multicolumn{2}{|c|}{ Stage 2} & \multirow[b]{2}{*}{$\begin{array}{l}\text { Change in } \\
\text { costs } \\
£ \text { sterling }\end{array}$} \\
\hline & $\begin{array}{c}\text { Patients } \\
n\end{array}$ & $\begin{array}{c}\text { Cost } \\
£ \text { sterling }\end{array}$ & $\begin{array}{c}\text { Patients } \\
n\end{array}$ & $\begin{array}{c}\text { Cost } \\
£ \text { sterling }\end{array}$ & \\
\hline 1 & 4733 & 8709 & 2110 & 591 & -8118 \\
\hline 2 & 8106 & 103189 & 6301 & 72398 & -30791 \\
\hline $3 a$ & 1078 & 22024 & 2931 & 54341 & 32317 \\
\hline $3 b$ & 778 & 24702 & 2098 & 62164 & 37462 \\
\hline 4 & 823 & 30303 & 2078 & 72328 & 42025 \\
\hline 5 & 131 & 5938 & 131 & 5938 & 0 \\
\hline Total & 15649 & 194865 & 15649 & 267760 & 72895 \\
\hline
\end{tabular}

Costs are presented in pounds sterling.

The sample size of 102 nationally distributed practices and 17,206 patients with a recorded diagnosis of asthma is large, but not free from bias. There is an over representation of fundholding and large practices (table 1) although the proportion of patients at each treatment step in the sample was independent of practice size and fundholding status. The diagnosis rate of asthma of $5.8 \%$ of adults is comparable to other figures $[12,16]$.

Analysis of Prescribing Activity Analysis Data (PACT) gives a national picture of antiasthma prescriptions, from which a bronchodilator/prophylactic ratio can be derived. Unfortunately PACT data does not allow determination of treatment step and is not linked to diagnostic data, hence the decision to study practices where diagnostic and prescribing information was available.

This study shows the proportion of adult asthmatics at each step of the BTS guidelines. The figures are based on what doctors actually prescribed and so, taken in conjunction with Warner's figures for children [17] (using a similar methodology), may serve as a baseline for comparative work. $27.5 \%$ of the current sample of patients were receiving no preventative therapy at all. Almost half were at Step 2 .

The costs and treatment patterns reported here are actual real life costs incurred by the 102 practices studied. While the reasons for each prescription cannot be ascertained, it is encouraging to find that $91 \%$ of patients were receiving treatment that accords with the 1993 BTS guidelines. The remaining $9 \%$ had received unorthodox combinations of drugs (e.g. salbutamol and theophylline, salmeterol and salbutamol) not classifiable within the guidelines and have not therefore been included in the calculations in table 4 . Such choice of treatment could be for good reasons pertinent to the individual patient or could represent suboptimal management. However, the cost of treatments given to this $9 \%$ subsample were close to the average costs of the $91 \%$ of patients that were "within" the guidelines.

The 1993 BTS guidelines revision was used rather than World Health Organisation (WHO) guidelines, in order to reflect contemporary UK standards, and no attempts were made to retrospectively incorporate new therapies or guideline revisions into the analysis.

The inclusion criteria for patients was a Read code diagnosis linked to asthma and an antiasthma prescription within a 6 month period. It is not possible to comment on any possible seasonal effect on the dataset. Children were 
excluded but it is possible that some adults with both chronic obstructive airways disease and asthma have been included. Validation studies on similar databases have shown that information from manual medical records was recorded on the practice computer over $90 \%$ of the time and the indication for prescribed drugs was present in over $95 \%$ of instances [18]. The Read Code [10] is preferred to the International Classification of Disease (ICD) code by most UK GPs.

One must be cautious when using prescription data to infer patterns of human behaviour or standards of clinical care. Many patients do not cash all their prescriptions or take them as intended [19]. Often inhalers are discarded before they are completely empty. Guidelines recommend that patients who are well controlled can have their treatment "stepped down" but the current analysis could take no account of this and neither could it allow for patients whose treatment ought to be increased by more than one step.

A high requirement for beta-agonists is an indicator of poor control. The BTS guidelines suggest that patients should have their treatment stepped up from one when usage exceeds one dose (two puffs) per day. Adopting this definition and based on actual beta-agonist prescription over 12 months, any patient deemed to be poorly controlled on the basis of beta-agonist usage at one guidelines step was moved to the relevant medication at the next step. A high usage rate was more frequent when the instructions given with the prescription were to use it regularly rather than "as required" but were still high in the "as required" subgroup and thus are likely to indicate a high level of symptoms requiring relief.

This analysis assumed patients not taking excessive amounts of beta-agonists were well controlled, but it is accepted that this will have been inaccurate in many cases.

The mean use of beta-agonists in the whole group was 5.4 puffs per day and thus the conclusions would be little changed by adopting a higher threshold of more than 3 puffs per day. The data cannot make allowance for other possibilities including teaching inhaler technique and educating the patient in the importance of taking regular medication as alternatives to increasing the prescribing step.

The debate on generic versus proprietary prescribing [20] is beyond the scope of this paper. Some costs due to "ideal" asthma treatment could be offset by making savings by use of generic products, where they exist. The costings in this paper represent the current proportion of generic products in use.

These qualifications mean that the $37 \%$ increase in asthma prescribing costs reported in this model is likely to be at the top end of what would actually occur in practice. It is not possible from prescribing data to estimate by how much the current figure may overestimate the true picture.

Cost estimates in this paper are confined to those of prescribed medication. The care of asthma involves cost to patients, primary care and hospitals. In the complex matrix of the cost of asthma care within the Health Service change in prescribing costs will alter costs elsewhere. An increase in the use of preventative therapy will increase GPs costs in the short term. This could lead to improvements in patients' quality of life and possibly result in a reduction in primary care costs (such as emergency call outs) and possibly even a reduction in hospital costs if admission rates and outpatient consultations are reduced [13]. Irrespective of these economic considerations, from a patient perspective the clinical message of this paper is that overuse of beta-agonists treatment by asthmatics is widespread and deserves attention in its own right.

The single practice study of PrICE [21], NAISH et al. [22] district survey, the study of children by WARNER [17] and the work of MCCARTHY et al. [9] have highlighted the issue that optimal asthma care may mean higher prescribing costs. The data set in this paper supports their findings. The Audit Commission figure of $£ 75$ million per annum "underspend" on antiasthma treatments may be an underestimate of the true need. This study suggests that the true figure could be as much as $£ 145 \mathrm{~m}$, representing a $37 \%$ increase in prescribing costs for adults alone. Clinicians face the dilemma of whether to bow to cost containment pressures or to opt to provide treatment in line with current consensus guidelines. Patients practitioners and politicians will need to decide what priority ideal asthma treatment should have within the Health Service.

\section{Appendix - assumptions used in methods section}

1) Patients whose therapy was changed during the review were classified according to their most recent treatment regime.

2) Step 3 of the BTS guidelines incorporates an alternative for those patients who experience problems with high-dose inhaled steroids. This is made more explicit in the most recent 1997 revision [23]. In the reallocation of patients to the BTS steps, the number of patients moved from step 2 to the two alternative regimens at step 3 reflected the relative proportion of asthmatics who were at step $3 \mathrm{a}$ and $3 \mathrm{~b}$ in the original allocation.

3) Products which were introduced subsequently to the publication of the BTS guidelines were included in the step which was most appropriate as suggested by their data sheet indications. Fluticasone propionate was incorporated on the basis that it is equivalent in efficacy to beclomethasone dipropionate at half the dose. (Confirmed in the 1997 revision of the guidelines [23]).

4) The relatively small $(<2 \%)$ number of patients who were prescribed only an oral beta-agonist were included in step 1.

5) While the daily dosage a patient should take was indicated on the majority of prescriptions issued, the defined daily dosage specified by the WHO was applied to those prescriptions for inhaled corticosteroids where the daily dosage could not be ascertained. The WHO specifies 8 puffs a day for salbutamol which is clearly in excess of consensus guidelines so this has been adjusted to a 2 puffs per day defined daily dose for the current analysis.

6) Patients receiving 1,2 or 3 oral steroid prescriptions were classified as taking short courses with those receiving 4 or more oral steroid prescriptions classified as receiving regular oral steroid therapy.

7) Frequency distributions were constructed for each class of medication prescribed within each step of the guidelines. These distributions showed the number of prescriptions for different dosage levels of each drug strength. For each of these drug strengths, a cost per dose was derived from the British National Formulary [24]. This cost was then combined with the various daily dosage levels to produce daily and monthly dosage costs. These monthly 
dosage costs were then multiplied by the corresponding number of prescriptions, summed for each class of medication and divided by the total number of patients prescribed this class of medication. These average monthly treatment costs per head were then summed within each of the BTS steps.

8) In the costing exercise, analysis was restricted to the most commonly prescribed daily dosages for each drug strength, defined as those comprising the first $90 \%$ of the prescriptions for each drug strength shown by the frequency distribution. The costings reflect the proportion of generic products in use at the time of the study.

9) Frequency of use of beta-agonist inhalers was determined from the DIN Database from the 12 months from April 1993 to March 1994. A period of 12 months was chosen to assess patients' mean daily usage of relief medication. The mean number of inhalers issued by patients over 12 months was then multiplied by the number of puffs per inhaler (typically 200 puffs) and divided by 365 to establish the mean number of puffs of beta-agonist a patient used on a daily basis. The figure of 200 puffs per inhaler did give an allowance for patients test firing their inhalers prior to use since the majority of beta-agonist inhalers actually contain some excess medication. This calculation also assumed that patients used all of the medication available in each inhaler that they were prescribed. 10) The following levels of short-acting inhaled betaagonist were used for the movement of patients between steps, more than two puffs daily for metered dose inhalers, more than one puff daily for breath-operated inhalers and more than once daily for nebulizer and respiratory solutions.

11) Oral beta-agonist use was not used as a marker of asthma control because patients are often instructed to use oral formulations on a regular basis.

12) On the basis that patients moving to a new, higher step of the guidelines should be better controlled, it was considered appropriate to assume/allow a minimal usage of relief medication across all steps (based on one puff a day) rather than the actual amounts.

13) Results were then compared with the costs found earlier to determine how much additional spending might be required by the pursuit of "ideal", asthma treatment.

14) During the 3 years ending March 1994, there were $36,507(5.8 \%)$ patients aged 18 and above who received asthma therapy for a diagnosis of asthma from a population base of 627,753 patients. For the purposes of this work, a study period of 6 months was chosen as it was considered that the majority of asthmatics would consult their general practitioner at least once during this time. Limiting the study period to 6 months also served to minimize the number of patients who would undergo a treatment change during this study. A diagnosis rate of $5.8 \%$ was used for the calculations in the discussion.

Acknowledgements. The authors thank the Doctors Independent Network for allowing the use of their data and B. Smith for secretarial help.

\section{References}

1. Burney PG, Chin S, Rona RJ. Has the prevalence of asthma increased in children? Evidence from the national study of health and growth 1973-86. BMJ 1990; 300: $1306-1310$

2. Strachan DP, Anderson HR. Trends in hospital admission rates for asthma in children. BMJ 1992; 304: 819-820.

3. Hyndman SJ, Williams DRR, Merrill SL, Lipscombe JM, Palmer CR. Rates of admission to hospital for asthma. BMJ 1994; 308: 1596-1600.

4. Anderson HR, Butland BK, Strachan DP. Trends in prevalence and severity of childhood asthma. BMJ 1994; 308: $1600-1604$.

5. Alderson M. Trends in morbidity and mortality from asthma. OPCS HMSO1987.

6. Mitchell EA, Anderson HR, Freeling P, White PT. Why are hospital admission and mortality rates for childhood asthma higher in New Zealand than in the United Kingdom? Thorax 1990; 45: 176-182.

7. Jones KP, Charlton IH, Middleton M, Preece WJ, Hill AP. Targeting asthma care in general practice using a morbidity index. BMJ 1992; 304: 1353-1356.

8. Grampian Asthma Study of Integrated Care (GRASSIC). Integrated care for asthma: a clinical, social and economic evaluation. BMJ 1994; 308: 559-564.

9. McCarthy TP, Taylor MD, Richardson PD. The management of asthma using clinical protocols: is it cost effective, and does it improve patients lifestyles? $\mathrm{Br} \mathrm{J} \mathrm{Med}$ Econ 1992; 2: 13-24.

10. Charlton I, Charlton G, Broomfield J, Mullee M. Education of peak flow and symptoms only self management plans for control of asthma in general practice. $B M J 1990$; 301: 838-842.

11. Charlton I, Charlton F, Broomfield J, Mullee M. Audit of the effect of a nurse run asthma clinic on workload and patient morbidity in a general practice. Br J Gen Pract 1991; 41: 227-231.

12. Barritt PW, Staples EB. Measuring success in asthma care: a repeat audit. Br J Gen Pract 1991; 41: 232-236.

13. Bryce FP, Neville RG, Clark RA, Crombie IK, MacKenzie P. Controlled trial of an audit facilitator in the diagnosis and treatment of childhood asthma in general practice. $B M J$ 1995; 310: 838-842.

14. British Thoracic Society and others. Guidelines on the management of asthma. Thorax 1993; 48: S21-S24.

15. Audit Commission. A prescription for improvement. 1994. HMSO London. ISBN 0118861026.

16. Neville RG. Case finding of asthma patients. Pract 1990; 234: 417-418.

17. Warner JO. Review of prescribed treatment for children with asthma in 1990. BMJ 1995; 311: 663-666.

18. Jick H, Jick S, Derby L. Validation of information recorded on general practitioner based computerised data resource in the United Kingdom. BMI 1991; 302: 766-768.

19. Cochrane GM. Therapeutic compliance in asthma: its magnitude and implications. Eur Respir J 1992; 5: 122-124.

20. Dowell JS, Snadden D, Dunbar JA. Changing to generic formulary: how one fundholding practice reduced prescribing costs. BMJ 1995; 310: 505-508.

21. Price DB. Patterns of prescribing of inhaled steroids over a seven year period in a general practice and its implications. Thorax 1995; 50 (4): 443.

22. Naish J, Sturdy P, Toon P. Appropriate prescribing in asthma and its related cost in East London. BMJ 1995; 310: 97-100.

23. British Thoracic Society and others. Revised British Asthma Guidelines. Thorax 1997; 52(1): S1-S21.

24. British National Formulary. Wallingford, UK, The Pharmaceutical Press, 1994 